\title{
LETTERS
}

\section{Daily physical activity after bronchoscopic lung volume reduction: a pilot study}

\section{To the Editors:}

Daily physical activity is an important outcome variable in patients with chronic obstructive pulmonary disease (COPD) and has shown to be mainly associated with dynamic lung hyperinflation [1]. Physical inactivity is known to cause muscle deconditioning, which increases the ventilatory requirements during exercise, and in turn increases lung hyperinflation and worsens dyspnoea, thus contributing to a downward spiral [2]. This is especially true in patients with emphysema, in which destruction of alveolar tissue can result in progressive static and dynamic lung hyperinflation. Moreover, physical inactivity is a strong predictor of mortality in COPD patients [3]. Notwithstanding the beneficial effects of regular physical activity, physical activity levels in COPD patients are low, especially in those with severe COPD [4].

Lung volume reduction (LVR) by bronchoscopic techniques is an innovative and increasingly applied treatment method targeted at improving lung hyperinflation. Endobronchial devices are implanted in emphysematous parts of the lung to reduce hyperinflation. This may improve the mechanical properties of the remaining lung and the efficiency of the inspiratory muscles. Consequently, this may lead to reduction of dyspnoea during exertion and improve functional capacity of the body. Theoretically, after LVR a COPD patient's physical activity level may improve, which would be beneficial for an independent lifestyle of the patient and for restoration of social participation. However, so far physical activity has never been measured before and after LVR. We therefore investigated the potential beneficial effects of bronchoscopic LVR on the physical activity level of these severely disabled COPD patients, and investigated whether decreased lung hyperinflation is associated with increased physical activity.

We performed a pilot study on 16 patients with severe emphysema who participated between July 2009 and August 2010 in bronchoscopic LVR with coils intervention studies (NCT01220908 and 01328899). The studies were approved by the local ethics committee and all patients provided informed consent. Prior to the bronchoscopic LVR treatment, physical activity was examined with a triaxial accelerometer together with lung function, lung volumes, exercise capacity, dyspnoea severity and self-efficacy. 6 months after the bronchoscopic LVR, all measurements were repeated.

Physical activity was measured in a performance-based manner with a triaxial accelerometer, using the DynaPort (McRoberts, the Hague, the Netherlands). The Dynaport is a small device which is worn around the waist. Patients were instructed to wear the DynaPort continuously for a period of 1 week. The DynaPort is able to detect physical activity (standing, locomotion, shuffling, lying and sitting), to measure steps and to estimate physical activity level (PAL) based on energy expenditure. PAL is calculated as total energy expenditure divided by basal metabolic rate. The DynaPort has proven to be an accurate tool to measure postures and gait in COPD patients [5]. Forced expiratory volume in $1 \mathrm{~s}$ (FEV1) and lung volumes were measured according to European Respiratory Society/American Thoracic Society guidelines. Exercise capacity was determined using the 6-min walk distance (6MWD) [6]. Dyspnoea severity was determined using the modified Medical Research Council Dyspnoea scale (mMRC) [7]. Self-efficacy in physical abilities was measured using the Dutch version of the Perceived Physical Activity Scale (LIVAS questionnaire) [8].

Of the 16 patients who were included at baseline, two were lost to follow up. Consequently, 14 patients were included in this analysis: four males (29\%), median age $62.5 \mathrm{yrs}$, and median FEV1 $28 \%$ predicted. Physical activity was low at baseline: median number of steps per day was 2,084, and median percentage activity (standing, locomotion and shuffling) was 17.6\% (table 1).

After 6 months, no significant changes in physical activity, exercise capacity or self-efficacy were found (table 1). Static lung hyperinflation measurements improved significantly above the recently calculated minimal important difference [9], and dyspnoea severity decreased by 1 point on the mMRC scale $(\mathrm{p}=0.06)$.

In line with our hypothesis, decreased RV/TLC was significantly associated with decreased dyspnoea severity ( $\mathrm{rho}=0.65, \mathrm{p}=0.01$ ). However, in contrast with our hypothesis this was not associated with changes in physical activity outcomes. Although exercise capacity (6MWD) did not improve significantly after bronchoscopic LVR, this was positively associated with changes in physical activity as assessed by percentage activity (rho $=0.55$, $\mathrm{p}=0.04)$, number of steps per day ( $\mathrm{rho}=0.57$ and $\mathrm{p}=0.03)$, and borderline significant with dyspnoea (rho $=-0.48, \mathrm{p}=0.09)$.

In summary, this pilot study showed that there was no improvement in physical activity 6 months after bronchoscopic LVR, despite significant improvements in static lung hyperinflation. Furthermore, decreased lung hyperinflation was not associated with improved physical activity or exercise capacity, in contrast to its significant association with reduced dyspnoea severity.

This study indicates that a new treatment method in COPD, such as bronchoscopic LVR, can substantially improve lung hyperinflation and dyspnoea severity. The improvement in dyspnoea could indicate that patients might perform the same activities more comfortably than before the treatment. However, an increase in physical activity is not automatically warranted. 


\begin{tabular}{lccc}
\hline TABLE 1 & $\begin{array}{l}\text { Clinical characteristics at baseline and after } \\
6 \text { months }\end{array}$ \\
\hline Variable & Baseline & $\mathbf{6 - m o n t h}$ follow up & p-value \\
\hline RV \% pred & $223(184-267)$ & $205(134-223)$ & $\mathbf{0 . 0 0 1}$ \\
RV/TLC \% & $61.4(55.4-67.4)$ & $56.7(48.3-65.3)$ & $\mathbf{0 . 0 0 8}$ \\
FEV $\mathbf{1} \%$ pred & $28(22-42)$ & $32(15-58)$ & 0.35 \\
mMRC score & $3(2-4)$ & $2(2-4)$ & 0.06 \\
6MWD m & $336(200-451)$ & $348(140-477)$ & 0.22 \\
Activity \% & $17.6(8.1-27.9)$ & $15.0(7.7-26.4)$ & 0.29 \\
Steps per day & $2084(374-5800)$ & $2426(321-5721)$ & 0.68 \\
Physical activity level & $1.51(1.33-1.61)$ & $1.50(1.37-1.66)$ & 0.55 \\
Self-efficacy, LIVAS total & $29(13-39)$ & $30(20-42)$ & 0.28 \\
score & & & \\
\hline
\end{tabular}

Data are presented as median (range), unless otherwise stated. RV: residual volume; \% pred: \% predicted; TLC: total lung capacity; FEV1: forced expiratory volume in $1 \mathrm{~s}$; mMRC: modified Medical Research Council dyspnoea index; 6MWD: 6-min walk distance. Baseline and follow-up measurements were compared with Wilcoxon signed-rank test (significant p-values are shown in bold)

Other treatment methods that increase functional capacity in COPD patients have shown similar results. For example, a recent review showed that participation in a pulmonary rehabilitation programme does not automatically result in increased physical activity [10]. Furthermore, although lung transplantation improves lung function, physical activity remains below normal values and is significantly worse than in matched healthy controls [11]. Together, this suggests that although patients have larger pulmonary reserves to function at higher physical activity levels, other factors are apparently more important. These could be physical factors like chronic deconditioning or atrophic muscles, and/or psychological factors, such as motivation to be physically active, anxiety or anticipated breathlessness.

This study implies that it is important to provide a physical activity enhancement programme after LVR. Such an intervention should include a structured exercise programme with specific attention for atrophic muscles. Additionally, in our opinion, exercises should be combined with counselling consisting of promotion of physical activities in daily life in an attempt to achieve long term results.

We are aware that the number of patients is low and that our study lacked a control group. A large randomised controlled trial would be useful to confirm our results.

In conclusion, despite the low number of patients, this is the first study that shows data on physical activity in a performancebased manner after LVR. Unexpectedly, physical activity did not significantly improve after the intervention, while static lung hyperinflation and dyspnoea severity did. This suggests that the improved pulmonary capacity is actually not used by the COPD patients for physical activities in daily life, probably also due to psychological reasons. Consequently, our study indicates that a short pulmonary rehabilitation programme with counselling on the promotion of physical activity in daily life should be considered after such treatments.
Jorine E. Hartman*,\#, H. Marike Boezen ${ }^{\#, \text {, }}$ Sanne Heintzbergen ${ }^{+}$, Mathieu H.G. de Greef ${ }^{+}$, Karin Klooster, ${ }^{*, \#}$, Nick H.T. ten Hacken ${ }^{*, \#}$, Dirk-Jan Slebos*,\# *Dept of Pulmonary Diseases, University of Groningen, University Medical Center Groningen, "Groningen Research Institute for Asthma and COPD, University of Groningen, University Medical Center Groningen, "Dept of Epidemiology, University of Groningen, University Medical Center Groningen, and ${ }^{+}$Dept of Human Movement Sciences, University of Groningen, University Medical Center Groningen, Groningen, The Netherlands.

Correspondence: D-J. Slebos, Dept of Pulmonary Diseases AA11, University Medical Center Groningen, PO Box 30001, 9700 RB Groningen, The Netherlands. E-mail: d.j.slebos@umcg.nl

Statement of Interest: A statement of interest for D-J. Slebos and for the study itself can be found at www.erj.ersjournals.com/ site/misc/statements.xhtml

Acknowledgements: Measurements were supported by an unrestricted loan of the accelerometers by McRoberts BV, The Netherlands.

\section{REFERENCES}

1 Garcia-Rio F, Lores V, Mediano O, et al. Daily physical activity in patients with chronic obstructive pulmonary disease is mainly associated with dynamic hyperinflation. Am J Respir Crit Care Med 2009; 180: 506-512.

2 Cooper CB. The connection between chronic obstructive pulmonary disease symptoms and hyperinflation and its impact on exercise and function. Am J Med 2006; 119: 21-31.

3 Waschki B, Kirsten A, Holz O, et al. Physical activity is the strongest predictor of all-cause mortality in patients with COPD: a prospective cohort study. Chest 2011; 140: 331-342.

4 Watz H, Waschki B, Meyer T, et al. Physical activity in patients with COPD. Eur Respir J 2009; 33: 262-272.

5 Langer D, Gosselink R, Sena R, et al. Validation of two activity monitors in patients with COPD. Thorax 2009; 64: 641-642.

6 ATS Committee on Proficiency Standards for Clinical Pulmonary Function Laboratories. ATS statement: guidelines for the sixminute walk test. Am J Respir Crit Care Med 2002; 166: 111-117.

7 Bestall JC, Paul EA, Garrod R, et al. Usefulness of the Medical Research Council (MRC) dyspnoea scale as a measure of disability in patients with chronic obstructive pulmonary disease. Thorax 1999; 54: 581-586.

8 Bosscher RJ, Laurijssen L, de Boer E. Measuring physical selfefficacy in old age. Percept Mot Skills 1993; 77: 470.

9 Hartman JE, ten Hacken NHT, Klooster K, et al. The minimal important difference for residual volume in patients with severe emphysema. Eur Respir J 2012; 40: 1137-1141.

10 Troosters T, Gosselink R, Janssens W, et al. Exercise training and pulmonary rehabilitation: new insights and remaining challenges. Eur Respir Rev 2010; 19: 24-29.

11 Langer D, Gosselink R, Pitta F, et al. Physical activity in daily life 1 year after lung transplantation. J Heart Lung Transplant 2009; 28: $572-578$.

DOI: $10.1183 / 09031936.00072112$ 